\title{
Temas e figuras em Bufólicas
}

\author{
Luisa da Rocha BARROS (FFLCH-USP) \\ e Julia BORGES (FFLCH-USP)
}

RESUMO: "Bufólicas", de Hilda Hilst, reúne combinações inusitadas de poesia, fábulas, linguagem chula, temas tradicionais e figuras eróticas. Essa mistura tem efeito cômico, acentuado, também, pelo paralelismo temático-figurativo entre as poesias e contos de fadas. A oralidade é facilitada pelo uso predominante de redondilhas e de gírias.

PALAVRAS-CHAVE: Hilst; contemporânea; Bufólicas; temas; figuras.

ABSTRACT: "Bufólicas" (Hilda Hilst) is a queer combination of poetry, fables, vulgar language, traditional themes and erotic figures. This mixture may sound comic and this effect is empathized, as well, by the figurative and thematic parallelism between poetry and fairy tales. Orality is also an important element just like the use of slang words.

KEYWORDS: Hilst; Bufólicas; contemporary, themes, figures. 


\section{A literatura contemporânea e seus autores "desconhecidos"}

O seguinte trabalho nasce de discussões a respeito da literatura contemporânea brasileira e da sua valorização nos meios acadêmico e social. A intenção é propor estudo, discussão e leitura acerca da produção contemporânea. Tendo a Semiótica sido influenciada pela teoria literária para construir sua teoria, principalmente no que diz respeito ao nível discursivo, nada mais natural que ela, agora, proponha novos caminhos e temas a serem estudados.

Os escritores contemporâneos são pouco estudados na academia. Não só porque o tempo de vida de suas obras é menor, mas também pelo desinteresse da sociedade por escritores que não fazem parte do cânone literário. Não está em questão a importância de se estudar autores consagrados, todavia, eles são amplamente discutidos nas escolas, universidades e meios de comunicação.

Os livros didáticos para ensino médio, bem como as apostilas de cursinhos prévestibulares não abordam devidamente os escritores contemporâneos, restando a eles, pouquíssimas vezes, pequenos e vagos capítulos. São citados, às vezes, em algumas questões que desenvolvem temas históricos, geográficos ou gramaticais, sem ressaltar, entretanto o valor literário de suas obras.

É evidente que não é fácil estudar uma "corrente literária" sem um distanciamento histórico que permite que o olhar seja mais abrangente. Esse desafio, no entanto, é importante para a formação e discussão acadêmicas. Os autores contemporâneos criam a literatura do nosso tempo. Muitos ainda produzem o que permite compartilhar a experiência literária.

Muitas vezes esses escritores sentem-se insatisfeitos por não serem reconhecidos. E pouco se faz, principalmente na academia, para que haja uma conexão entre eles e interessados. Incluí-los na universidade poderia ser uma experiência enriquecedora e gratificante para ambas as partes. Pode-se citar como exemplo de iniciativa nessa direção um projeto da Universidade Estadual de Campinas, no qual Hilda Hilst dividiu as suas experiências como escritora com alunos e interessados. Esse contato com um colega renomado é muito importante para a formação de futuros escritores e de profissionais da área de Letras.

Nascida em Jaú em 1930, Hilda Hilst estudou na faculdade de direito do Largo São Francisco e viveu mais de vinte anos na "Casa do Sol", chácara próxima à Campinas, onde se dedicou plenamente à criação literária. Agraciada com sete prêmios literários, alguns de seus textos foram traduzidos para o francês, inglês, italiano e alemão. Sua obra divide-se em prosa, poesia e teatro. Faleceu em quatro de fevereiro de 2004. Numa mistura muito inteligente, ela fala do sagrado e do profano, usa termos medíocres e elevados, tons cômicos e sérios, faz prosa e poesia, podendo alcançar um lirismo transcendental ou um efeito cômico poderoso, sem vulgaridade ou pedantismo.

Após ter escrito a maior parte da sua obra e já obter reconhecimento da crítica, Hilda Hilst produz quatro livros eróticos com a tentativa de cativar mais leitores e popularizar a sua obra. O presente trabalho concentrar-se-á no livro Bufólicas, 1992. Ele faz parte da tetralogia obscena, da qual também fazem parte os livros: $O$ caderno rosa 
de Lori Lamby, de 1990; Contos de d'escarnio/ Textos grotescos, 1990; Cartas de um sedutor, 1991.

\section{Bufólicas - estilo e interdiscursividade}

Iniciando a análise de Bufólicas, o primeiro impacto que o título provoca é de seriedade, à medida que ele pode ser associado ao termo Bucólico. Outra associação imediata é o termo Bufo, que sugere a pretensão cômica. Parece que Hilda Hilst cria o termo Bufólicas, condensando essas duas palavras.

A palavra Bucólica remete a écloga, talvez a melhor representação da maioridade do bucolismo na literatura de língua portuguesa. Bufólicas, de fato, se assemelha à écloga (poesia pastoril geralmente dialogada). Ora, como veremos adiante, a oralidade é um elemento importante e geral no conjunto de poesias analisado. A palavra bufo, bufão que, alem de ser um ator que tem a missão de ser cômico e burlesco; lembra o ato de bufar. Bufando, Hilda expele sua poesia que, para alguns moralistas, que insistem em deixar de lado temas permanentemente presentes no cotidiano das pessoas, pode parecer reles, vulgar.

As sete poesias narrativas com seqüência lógica, que constituem o livro, aproximam-se da fábula. Todas elas apresentam as personagens, desenvolvem o enredo, realizam o desfecho e, por fim, a moral da história. As personagens são típicas dos contos de fada: reizinho, rainha, fadinha, anão. Uma poesia em forma de fábula associada a anomalias nos órgãos genitais, a homossexualidade, violência sexual, assuntos que em nossa cultura, são considerados tabu. .

A oralidade tem papel fundamental nos poemas de Bufólicas, nada mais natural, já que a fábula tem sua origem na cultura oral, com sua narrativa curta, que sempre é encerrada por uma moral implícita ou explicita. Nesse caso, a moral é explícita e é interessante o fato dela estar associada a temas eróticos. A temática erótica relacionada com personagens de contos de fada e estrutura das fábulas não se torna vulgar. Atinge, dessa forma, o caráter cômico que perdura durante todo o livro.

Mesmo com tom jocoso, que resulta da mistura de personagens tradicionais, rearticulados e desconstruidos, e o erotismo, discutem-se temas importantes na sociedade e que pouco se mencionam devido ao preconceito dirigido a eles. Homossexualidade, sexualidade reprimida, violência sexual, exploração financeira do sexo, repressão e autoritarismo são alguns desses temas.

Propõe-se, agora, deter-se na análise de algumas poesias específicas, para a maior compreensão da estrutura temática-figurativa dos textos. Assim como se pode relacionar o título do livro com os vocábulos Bufo e Bucólico, a temática erótica versus o conto-de-fadas torna-se inusitada. Comparar-se-ão, então, o poema A Cantora Gritante e o conto-de-fadas Branca de Neve e os Sete Anões, versão de Walt Disney:

Nos dois textos, a Cantora e Branca de Neve, sofrem da inveja de seus antisujeitos, agora transformados em atores: as vizinhas e a madrasta. Branca de Neve é uma mulher jovem, bonita, alva como a neve que cai. É considerada, pelo espelho mágico, a mulher mais bela do reino, superando, assim, sua madrasta. Tomada pela 
paixão da Inveja, a madrasta elabora um plano para matá-la. Transformando-se em velhinha, envenena uma maça e oferece-a a Branca de Neve que, após comê-la, dorme um sono profundo, do qual só acordará com o beijo apaixonado de seu príncipe.

A Cantora Gritante, por sua vez, também gera a paixão da Inveja. Com sua bela voz, excitava os homens da vizinhança, que se saciavam avidamente em suas mulheres. As vizinhas, Curvadas, claudicantes/de xerecas inchadas/ maldizendo a sorte, unem-se para acabar de uma só vez com o mal que as atormentam, e, num ato de violação sexual, calam a bela voz da Cantora.

Pode-se dizer daí que existe um paralelismo tanto temático como figurativo, em determinados momentos nos textos. Nos dois casos as motivações para a eliminação da causa da inveja são parecidas: Branca de Neve era mais bela do que a madrasta e a Cantora Gritante tinha o poder de excitar os maridos, assim, a atenção masculina tratase do estopim para as ações violentas. Nota-se que as qualidades invejadas são qualificadas de maneira parecida. A beleza de Branca de Neve muito vem da sua pele alva e a voz da Cantora é assim descrita:

Cantava tão bem

Subiam-lhe oitavas

Tantas tão claras

Na garganta alva

A cor branca é, portanto, predominante na caracterização dos dois atoresprotagonistas. Há, porém outro paralelismo na forma em que a destruição da fonte de insatisfação é completada. Em ambos os textos os castigos recebidos são por via oral: A Branca de Neve come a maça envenenada; a Cantora Gritante tem sua voz calada pelo enorme nabo do Jumento Fodão.

$\mathrm{O}$ quadro seguinte pretende esquematizar como o percurso figurativo dos dois textos é gerado a partir do mesmo tema:

\begin{tabular}{|c|c|c|}
\hline & $\begin{array}{l}\text { Cantora } \\
\text { Gritante }\end{array}$ & $\begin{array}{l}\text { Branca de } \\
\text { Neve }\end{array}$ \\
\hline Causa & $\begin{array}{l}\text { Beleza da } \\
\text { voz }\end{array}$ & $\begin{array}{l}\text { Beleza } \\
\text { física }\end{array}$ \\
\hline invejosas & Vizinhas & madrasta \\
\hline $\begin{array}{l}\text { desperta o } \\
\text { interesse de }\end{array}$ & $\begin{array}{l}\text { Maridos que } \\
\text { ficam às } \\
\text { pampas } \\
\text { excitados } \\
\end{array}$ & $\begin{array}{l}\text { Homens } \\
\text { do reino } \\
\text { que a } \\
\text { admiram }\end{array}$ \\
\hline insatisfação & $\begin{array}{l}\text { Curvadas, } \\
\text { claudicantes, } \\
\text { de xerecas } \\
\text { inchadas }\end{array}$ & $\begin{array}{l}\text { Despeito } \\
\text { em } \\
\text { relação à } \\
\text { revelação } \\
\text { do } \\
\text { espelho }\end{array}$ \\
\hline
\end{tabular}




\begin{tabular}{|l|l|l|}
$\begin{array}{l}\text { Planos de } \\
\text { destruição }\end{array}$ & Calar a voz & $\begin{array}{l}\text { Matar } \\
\text { Branca }\end{array}$ \\
\hline Meio & $\begin{array}{l}\text { Jumento } \\
\text { Fodão }\end{array}$ & Maça \\
\hline & $\begin{array}{l}\text { Violação } \\
\text { bem } \\
\text { sucedida }\end{array}$ & $\begin{array}{l}\text { Morte mal } \\
\text { sucedida }\end{array}$ \\
\hline
\end{tabular}

Por se tratar de contos populares e de cultura oral, os contos de fada podem possuir diversas versões. Hilda Hilst toma proveito disso e escreve as suas versões para contos tão difundidos na cultura ocidental. O paralelo com A Cantora Gritante e A Branca de Neve dá conta disso, mas o exemplo mais peculiar, o que mais explicita identidade, é o conto A Chapéu.

A leitura de diversas versões de $A$ Chapeuzinho Vermelho mostra que, cada vez mais, a história se torna moralizante, seja devido aos conselhos dados pela sua mãe, seja por causado castigo destinado ao lobo. O tema da ingenuidade de Chapeuzinho/Chapéu, no entanto, se mantêm.

$\mathrm{Na}$ versão de Charles Perrault, Chapeuzinho Vermelho simplesmente atende ao pedido da mãe sem receber advertência alguma em relação ao caminho a seguir, nem tão pouco é salva de dentro do lobo. Todavia, a mesma história pode ser encontrada na versão dos Irmãos Grimm, na qual Chapeuzinho desobedece à mãe, e ao Lobo é punido de maneira cruel e violenta: tem sua barriga cortada pelo caçador que após retirar as duas, preenche com pedras o espaço por elas deixado. Quando o lobo acorda, se assusta com os três que o observam e salta da cama. O Lobo morre com a queda.

A versão de Hilda parece se distanciar mais da moralização da nossa cultura cristã e patriarcal. Vale dizer que as personagens da poesia de Hilda apenas lembram os nomes do conto original. Todas as figuras que possam fazer alusão ao sexo em Perrault, são explicitas em Hilda Hilst:

"Chapeuzinho Vermelho despiu-se e se meteu na cama"

"Levanta a aldraba que o ferrolho sobe"

"O malvado lobo atirou-se sobre chapeuzinho Vermelho e a comeu"

(PERRAULT. 1989: 52-55)

A Chapéu não só aproxima-se, como nos outros poemas, da fala pelo ritmo (plano da expressão), mas também pela forma da enunciação (plano do conteúdo). Nesse ponto ela é notável por apresentar os diálogos, predominando a enunciação enunciativa por quase todo o poema.

Em A Rainha Careca, os programas narrativos protagonizados pelos dois sujeitos têm, agora, com a desembreagem, o tempo e o espaço da fantasia, onde se configuram a ação dos dois atores, a rainha e o biscate. Os exemplos que seguem mostram a configuração temporal e espacial:

Que há tempos avistara. 
Um dia...

Passou pelo reino

Convocado ao palácio

No seu quarto.

A falta de pêlos pubianos da rainha Ula explica, inicialmente, o tema da sexualidade reprimida. A temática é recoberta pela isotopia figurativa que remete à falta de pêlos e o desejo de Ula de tê-los. Assim, o poema é repleto de investimentos semânticos e figuras que se referem ao problema da rainha: cabeleira farta, careca, o monte lisinho, tênue fiozinho, farta de cabelos, biscate peludo, pentelhos, arrancou do próprio peito os pelos, cabeluda, tufo.

As fábulas, em geral, apresentam um clímax. Em A Rainha Careca não é diferente. Quando o poema chega ao clímax, o leitor é tomado por uma surpresa que é compartilhada com Ula. O problema da rainha não eram os pêlos, e sim a castidade a que ela estava destinada.

Assim como nos contos de fada, os poemas de Bufólicas são ótimo exemplo de isotopia temática e figurativa com relação às fábulas. Outro ponto em comum é a forma. São escritos em versos livres, assim como algumas versões de fábulas, apresentam rimas internas, assonâncias e aliterações que ditam o ritmo dos versos e, principalmente, a moral da história. Comparando $O$ Anão Triste com $O$ Cachorro e sua Sombra, de Esopo, é possível verificar que o referente dos textos é o mesmo, porém o enfoque figurativo é outro.

Um cachorro, ao cruzar uma ponte Sobre um riacho carregando um pedaço de carne na boca, viu sua própria imagem refletida na água e pensou que fosse outro cachorro com um pedaço com o dobro do tamanho do que carregava.

Ele então largou sua carne, e, Ferozmente atacou o outro cachorro Para tomar-lhe aquele pedaço que Era bem maior que o seu.

Agindo assim ele perdeu ambos; Aquele que tentou pegar na água, Pois era apenas um reflexo; e o seu Próprio que caiu no riacho e foi Levado pela correnteza. Moral da História: 
Quem desiste do certo pelo duvidoso

É tolo duas vezes imprudente.

Mais uma vez o tema (moral da história) é o mesmo e as figuras adotadas são diversas. $\mathrm{O}$ cachorro buscava um pedaço de carne maior que o dele. $\mathrm{O}$ anão Cidão queria um pênis menor, pois quando ativado, virava a sua terceira perna. Dessa maneira ele não podia meter o ganso na tia nem na rodela do negão.

Ambos buscavam satisfazer desejos próprios. O cachorro: satisfazer sua vontade de comer; o anão: satisfazer seu desejo sexual. Nos dois casos não há obtenção de sucesso por imprudência.

Nota-se a recorrência de figuras associadas ao tema-tabu sexo. Talvez daí parta o interesse de abordá-lo. Observa-se a repetição de palavras relacionadas com o mesmo tema, coesão lexical, em cada poema:

O Reizinho Gay: pintudão, gay, peroba, entre as coxas grossas, pintudo, bronha, falo, mastruço, buraco negro, ganso, cu cabeludo.

A Rainha Careca: passarinha, monte lisinho, peludo, pentelhos, penetrando-lhe os meios, gemeu Ula de felicidade, prostituta, tufo.

Drida, a Maga Perversa e Fria: mastruço, cuzaço, dito cujo, rodela, buraco fundo, gay, enrabava. fornicam.

A Chapéu: gruta, língua, toca, bichona peluda, choca preta, nabo,buraco,

O anão Triste: pau em riste, ganso, rodela do negrão, porongo era longo, bastão, terceira perna, estrovenga, mastruço gigante, tico de pau, bimba, berimbau, fole, tesão.

A Cantora Gritante: excitados, enfiavam os bagos, xerecas inchadas, jumento Fodão, baixios, eternizou o nabo.

Filó, a Fadinha Lésbica: a cona era peluda, lésbica, metia o dedo em todas as xerecas, bulia, beliscava, bastão grosso, troço, tomava um bastão no oiti, gozo gozoso, um arrepião nos meio, gemia e chorava de pura alegria, revirando os óinho, rombo na bunda, cacete.

Essa repetição contextualiza internamente a obra, tratando de forma despojada, prosaica temas anteriormente revestidos com outras figuras, como por exemplo, $A$ Chapeuzinho Vermelho de Perrault. Logicamente a escolha desses temas e figuras na construção do texto leva em conta o contexto ideológico, e se não vivêssemos num país moralista e machista como o Brasil o texto não seria cômico e não seria tão interessante como é.

\section{Oralidade e versificação em Bufólicas}

As redondilhas, por se tratar de versos curtos, aproximam-se da oralidade. Isso se deve ao fato de que o tempo de elaboração da fala é quase concomitante ao de execução. O verso de cinco sílabas é mais oral que o de dez. É mais fácil organizar 
mensagens mais curtas, assim como as frases produzidas pelos repentistas nordestinos, ou como nas literaturas de cordel e cantigas de roda. Hilda mantém a tradição literária à medida que aborda temas ligados a cultura oral (contos maravilhosos, de fada e fábulas) usando redondilhas.

Quando se escreve, tem-se mais tempo para elaborar o discurso, formam-se períodos mais longos com orações subordinadas. Ao falar, no entanto, o ato da enunciação e a elaboração do enunciado acontecem quase ao mesmo tempo, exigindo que os períodos sejam mais curtos. Nas redondilhas de Bufólicas parece, portanto, que a história está sendo contada por alguém, de forma dinâmica e com uso de palavras próprias da linguagem coloquial.

É importante salientar, também, a coesão que se dá entre o plano da expressão e o plano do conteúdo. Como já foi dito, a proximidade da oralidade de Bufólicas se dá por meio do ritmo e da tradição oral dos gêneros que ela parodia, abundantes na cultura popular brasileira.

Assim, a coesão se dá justamente na mistura da forma elevada da poesia com a objetividade da prosa, além da oralidade que os versos promovem e dos vocábulos chulos. Essa combinação gera o efeito cômico dominante, e sua manutenção é que deixa a obra coesa.

É comum na literatura contemporânea os autores subverterem as formas. O soneto é comumente usado para tratar de temas ditos elevados, no entanto o poeta Glauco Mattoso se vale dessa forma e a subverte tratando sexo da maneira coloquial e às vezes, chula. Ele não só trata de temas considerados inferiores como, ainda por cima, utiliza-se palavras de baixo calão que chocam até os leitores contemporâneos. Hilda Hilst também subverte as redondilhas, que apesar de não tratarem tradicionalmente de temas elevados, não usam comumente palavras grosseiras ou obscenas.

Por fim, o livro é ilustrado pelo cartunista Jaguar, artista engajado politicamente. Tanto o texto quanto as ilustrações mostram o erotismo de forma explícita, desta forma se completam para intensificar o efeito cômico da obra. A primeira ilustração vem acompanhada de expressão de Moliere "ridendo castigat mores", que significa rindo se castiga ou critica os costumes, portanto esse livro não é apenas uma forma de popularizar a obra, mas também de critica social e de entretenimento.

\section{REFERÊNCIAS BIBLIOGRÁFICAS}

BARROS, Diana Luz Pessoa de. Teoria do discurso - fundamentos semióticos. São Paulo: Humanitas, 2002

CÂNDIDO, Antônio. Formação da literatura brasileira vol.II. As formas de expressão. São Paulo: Martins, 1964.

COELHO, Jacinto do Prado (org.). Dicionário das literaturas portuguesa, brasileira e galega. Porto: Livraria Figueirinhas, 1960

HILST, Hilda. Bufólicas. São Paulo: Globo, 2002

PERRAULT. Charles. Contos de Perrault. Tradução: Regina Regis Junqueira. Belo Horizonte: Itatiaia, 1989. 


\section{Como citar este artigo:}

BARROS, Luisa da Rocha; BORGES, Julia. Temas e figuras em "Bufólicas". Estudos Semióticos, Número 2, São Paulo, 2006.

Disponível em <www.fflch.usp.br/dl/semiotica/es $>$. Acesso em "dia/mês/ano". 